Fluconazole or Daktacort. In the remaining cases no presumptive diagnosis was made but 10 patients were given empirical Trimovate cream, three had Metronidazole tablets, one had Dermovate cream and one had Betnovate cream. Seven patients did not receive any medication. In all but one case the balanitis had fully resolved within 6 weeks. In the persistent case, initial treatment was with Clotrimazole cream for presumed Candida; when the lesions persisted this was changed to Daktacort but a clear diagnosis was not made. However, he failed to attend for further follow-up so it is not known if the balanitis resolved with the change of treatment. No cases were referred for biopsy.

Conclusion The rate of persistent balanitis was extremely low in this cohort and all except one case resolved with treatment. This patient did not return for further review and was not referred for biopsy. Penile biopsy is recommended where the balanitis persists and the diagnosis remains unclear as in this case. A robust system of recall management is needed to ensure that appropriate action is taken in such cases.

\section{P139 EVALUATION OF A DEDICATED MULTI-DISCIPLINARY YOUNG PERSON'S INTEGRATED SEXUAL HEALTH CLINIC}

doi:10.1136/sextrans-2012-050601c.139

T Davis, S L Allstaff, C Cunningham.* NHS Tayside, Dundee, UK

Background Our local authority has the highest teenage pregnancy rate in Scotland. A needs assessment was undertaken and a dedicated young persons (YP) clinic was introduced for people aged 18 and under in partnership with the local youth health and information centre and the child protection team.

Aim To evaluate the 6-month pilot of a dedicated YP multi-disciplinary integrated sexual health clinic.

Methods All patients attending the YP clinic between January and June 2011 were included. Data collected included demographics, sexual orientation, STI diagnoses and the uptake of contraceptives. Data were also collected from an evaluation form offered to all patients.

Results 131 young people attended the YP clinic during the pilot period. 108 (81\%) were female and 23 were male of which 4 (17\%) were men who have sex with men. The mean age was 16 for both males and females (range 12-18). 61 (47\%) were under the age of 16. Chlamydia infection rates were high (24.4\%). Sub-dermal implants were fitted in $22.2 \%$ of eligible females. 75 young people completed evaluation forms (57.3\%). The majority found the clinic times suitable (95\%) and travelled to the clinic by public transport or on foot $(76 \%)$. Young people most frequently heard about the clinic from the local youth centre or from friends. Service users frequently commented positively on the partnership working with other agencies.

Conclusions The introduction of a YP clinic has been popular with service users. Due to the success of this service, a second clinic will be launched at the same site.

\section{P140 SETTING UP A YOUNG PERSON'S CONTRACEPTION AND SEXUAL HEALTH (CASH) SERVICE IN A SEMI-RURAL GP PRACTICE-THE FIRST YEAR}

doi:10.1136/sextrans-2012-050601c.140

0 Hum.* School Hill Surgery, Lewes, UK

Background The National Strategy for Sexual Health and HIV talks about improving access to genito-urinary medicine (GUM) services by providing Level 2 services in other settings, including primary care. Rural teenagers often find it hard to access GUM services due to distance and time constraints. They may also dislike consulting their own General Practitioners (GPs) due to concerns about confidentiality.

Aims/Objectives Poor access to sexual health and family planning services was noticed in our rural area. A small Level 2 service was set up within a GP practice in January 2011. It was designed in conjunction with, and widely promoted at, local schools and colleges. A walk in service, running once a week; it offers diagnosis and treatment of most STIs, registration for C card, and all forms of contraception including long acting reversible contraception (LARC). It also offers pregnancy testing, HIV testing, signposting and advice. Emergency contraception is offered at any time of the week. There are three members of staff, a GP, practice nurse and health care assistant.

Results 432 patients were seen, with a median age of 17, drawn from a large geographical area. $75 \%$ were female and $20 \%$ under 16 . New to follow-up ratio was 3:1. 261 chlamydia tests were offered with an $11 \%$ positivity rate. 137 young people have been registered for the $\mathrm{C}$ card, with a short education session, and LARC was discussed with 216 patients. 102 prescriptions for oral contraceptives were given and 23 injections of Depo Provera. 17 contraceptive implants and two coils were inserted. A patient satisfaction survey with a sample size of 38 showed high satisfaction ratings. Offering a service within the non-threatening environment of a GP surgery was approved highly, and most felt that their right to confidentiality had been upheld.

Conclusions In a semi-rural area, primary care can provide an effective, accessible and popular alternative to traditional $\mathrm{CaSH}$ services.

\section{P141 MARKETING SEXUAL HEALTH IN A BRAND CONSCIOUS WORLD: CAN WE MAKE SERVICES MORE ACCESSIBLE TO YOUNG PEOPLE?}

doi:10.1136/sextrans-2012-050601c.141

${ }^{1} 0$ Hum, ${ }^{2}$ R L Lee. ${ }^{1}$ School Hill Surgery, Lewes, UK; ${ }^{2}$ Rachel Lee Design, Brighton, UK

Background Adolescents are media-savvy and extremely brand conscious. Much promotional material for sexual health services is poorly designed. Little has been written about how this may influence their acceptability among young people.

Objectives A new CaSH service was set up in primary care. In order to make the service appealing and accessible to adolescents, a graphic designer was recruited to create concepts and ideas for the look of the new service.

Methods Following a broad search of current $\mathrm{CaSH}$ websites and leaflets nationally, many were found to be poorly designed and configured, using cliched teenage imagery and language. Focus groups were set up with local young people. Six possible logos were presented, first using the suggested service name in words only, then gradually introducing each of the logo options in colour. Opinions were sought at each stage.

Results/Discussion There were widely differing views about most of the designs. Any perceived use of teenage slang, or reference to sexual health or the NHS, was rejected. Leaflets were also seen as irrelevant and boring, and leading to possible breaks in confidentiality. One logo was favoured unanimously. A poster and website were designed based on this logo to develop the brand further. In place of a leaflet, a business style card was designed, bearing only a logo and website address, enhancing the services' confidentiality. The website is the key portal for adolescents to gain information in both a confidential and informative way. Promotion in schools and pubs has led to high brand recognition. Informal feedback from service users has shown a high acceptability of the cards and the logo is perceived as contemporary and relevant. 